$$
\begin{aligned}
& 1 N=39 \\
& 045656
\end{aligned}
$$

NASA/TM-97-206262

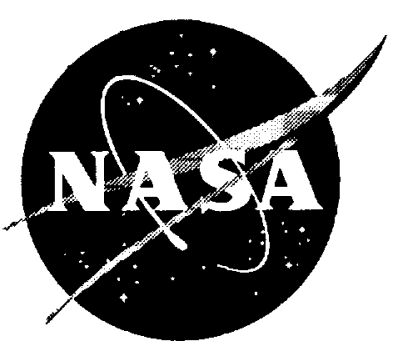

\title{
Independent Analysis of the Space Station Node Modal Test Data
}

Richard S. Pappa 


\section{The NASA STI Program Office ... in Profile}

Since its founding, NASA has been dedicated to the advancement of aeronautics and space science. The NASA Scientific and Technical Information (STI) Program Office plays a key part in helping NASA maintain this

important role.

The NASA STI Program Office is operated by Langley Research Center, the lead center for NASA's scientific and technical information. The NASA STI Program Office provides access to the NASA STI Database, the largest collection of aeronautical and space science STI in the world. The Program Office is also NASA's institutional mechanism for disseminating the results of its research and development activities. These results are published by NASA in the NASA STI Report Series, which includes the following report types:

- TECHNICAL PUBLICATION. Reports of completed research or a major significant phase of research that present the results of NASA programs and include extensive data or theoretical analysis. Includes compilations of significant scientific and technical data and information deemed to be of continuing reference value. NASA counter-part of peer reviewed formal professional papers, but having less stringent limitations on manuscript length and extent of graphic presentations.

- TECHNICAL MEMORANDUM. Scientific and technical findings that are preliminary or of specialized interest, e.g., quick release reports, working papers, and bibliographies that contain minimal annotation. Does not contain extensive analysis.

- CONTRACTOR REPORT. Scientific and technical findings by NASA-sponsored contractors and grantees.
- CONFERENCE PUBLICATION. Collected papers from scientific and technical conferences, symposia, seminars, or other meetings sponsored or co-sponsored by NASA.

- SPECIAL PUBLICATION. Scientific, technical, or historical information from NASA programs, projects, and missions, often concerned with subjects having substantial public interest.

- TECHNICAL TRANSLATION. Englishlanguage translations of foreign scientific and technical material pertinent to NASA's mission.

Specialized services that help round out the STI Program Office's diverse offerings include creating custom thesauri, building customized databases, organizing and publishing research results ... even providing videos.

For more information about the NASA STI Program Office, see the following:

- Access the NASA STI Program Home Page at http://www.sti.nasa.gov

- E-mail your question via the Internet to help@sti.nasa.gov

- Fax your question to the NASA Access Help Desk at (301) 621-0134

- Phone the NASA Access Help Desk at (301) 621-0390

- Write to: NASA Access Help Desk NASA Center for AeroSpace Information 800 Elkridge Landing Road Linthicum Heights, MD 21090-2934 
NASA/TM-97-206262

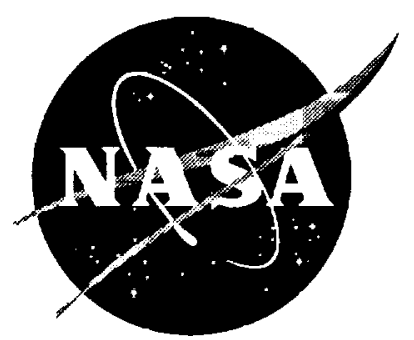

\section{Independent Analysis of the Space Station Node Modal Test Data}

Richard S. Pappa

Langley Research Center, Hampton, Virginia

National Aeronautics and

Space Administration

Langley Research Center

Hampton, Virginia 23681-2199 
Available from the following:

NASA Center for AeroSpace Information (CASI)

800 Elkridge Landing Road

Linthicum Heights, MD 21090-2934

(301) 621-0390

National Technical Information Service (NTIS) 5285 Port Royal Road

Springfield, VA 22161-2171

(703) $487-4650$ 


\title{
INDEPENDENT ANALYSIS OF THE SPACE STATION NODE MODAL TEST DATA
}

\author{
Richard S. Pappa \\ Structural Dynamics Branch \\ NASA Langley Research Center \\ Hampton, Virginia 23681 \\ E-mail: r.s.pappa@larc.nasa.gov
}

\begin{abstract}
With complex structures, comparison of independently derived sets of experimental modal parameters is an excellent way to increase confidence in the results. This paper presents modal identification results using the Eigensystem Realization Algorithm (ERA) on frequency response functions from the modal test of the Space Station Resource Node. The Resource Node is the first U.S.-built structure for the International Space Station. The modal test was conducted by the NASA Marshall Space Flight Center (MSFC) in January 1997 for the Boeing Company, who designed and built the Node. The ERA-calculated parameters are compared with independent results obtained by the MSFC test team using commercial software. There was excellent correlation of mode shapes between the two sets of results for the first 21 vibration modes of the structure up to $35 \mathrm{~Hz}$. From 35 to $50 \mathrm{~Hz}$, about 60 percent of 25 additional modes had excellent correlation. Natural frequencies and damping factors of most modes agreed within $0.1 \mathrm{~Hz}$ and 0.2 percent, respectively.
\end{abstract}

\section{INTRODUCTION}

Beginning with the launch of the Russian-built, U.S.financed, Functional Cargo Block (FGB) in June 1998, a consortium of 15 nations will begin assembly of the International Space Station (ISS), the largest scientific cooperative program in history (Ref. 1). (Note: Throughout the Space Station program, the "Functional Cargo Block" is referred to as the "FGB," which is the acronym of the Russian translation of the name.) The components of the ISS will be ferried to space over a period of approximately 5 years in 44 separate missions using both U.S. and Russian launch vehicles. At completion, the ISS will have a width (wingspan) of 356 $\mathrm{ft}$, a length of $290 \mathrm{ft}$, and a mass of nearly one million lbs. The pressurized interior is more than 46,000 cubic $\mathrm{ft}$, roughly equivalent to the passenger cabin volume of two 747 jetliners. It will provide living and working space for up to seven full-time occupants.
One month after the FGB is placed into orbit, the Space Shuttle will bring up the second component of the ISS known as Resource Node No. 1. It is a pressurized, cylindrical hub approximately $17.5 \mathrm{ft}$ long and $14 \mathrm{ft}$ in diameter with four radial ports and two axial ports. Attached to each axial port is an 8-ft-long Pressurized Mating Adapter (PMA) tunnel. One of the PMAs is the connecting passageway between the U.S. and Russian areas of the station. The other end of the Node will eventually connect to the U.S. Laboratory module. The radial ports provide additional attachment points for other structures including the U.S. Habitation module at the nadir port.

Figure 1 illustrates how the Resource Node will be attached to the FGB on Shuttle Mission STS-88 in July 1998. The Node rides to space longitudinally in the cargo bay of the Space Shuttle and is then rotated and remounted laterally by the robotic arm. The orbiter will then rendezvous with the FGB as shown. Connection occurs by mating the exposed upper end of the PMA with the axial docking port of the FGB.

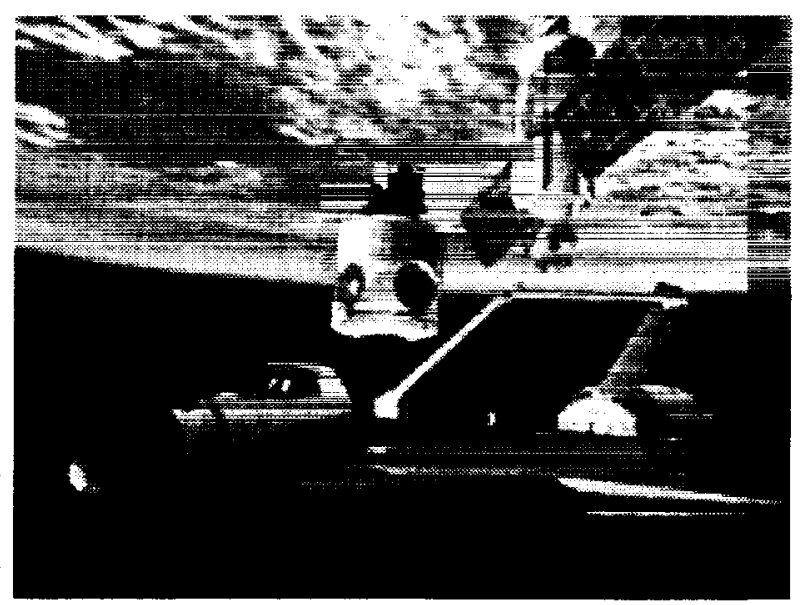

Fig. 1 - Assembly in Space of the Node and FGB

The Resource Node and the PMAs were designed and built under contract to NASA by the Boeing Company. In January 1997, the Dynamics Test Branch at the NASA Marshall Space Flight Center (MSFC), in collaboration 
with Boeing, conducted an extensive modal test of the Node at MSFC to validate the structural analytical model in accordance with NSTS 14046 and SSP 30599 (Refs. 23). The structure was mounted in a massive test fixture that constrained it in a manner similar to the boundary conditions of the Shuttle cargo bay. Using commercially available software, the test team identified 45 modes of vibration from 0 to $50 \mathrm{~Hz}$ (Ref. 4).

Prior to receiving the MSFC report containing their test results (Ref. 5), the NASA Langley Research Center (LaRC) performed an independent modal analysis of the same set of frequency response functions (FRFs) using their in-house-developed Eigensystem Realization Algorithm (ERA) (Refs. 6-7). LaRC received these FRFs as a test case for on-going research in the area of autonomous structural modal identification (Ref. 8). These data, one of the largest sets of FRFs ever measured in a modal test, were analyzed with the latest version of the autonomous ERA procedure, and the results are presented in this paper. The paper also compares the experimental modal parameters obtained by each of the two organizations.

The following section of the paper briefly describes the test structure and the test procedure. Typical FRF data and corresponding mode indicator functions appear in the next section to show the quality and complexity of the measurements. The remainder of the paper summarizes the ERA results and compares them with the test team results.

\section{TEST ARTICLE AND TEST PROCEDURE}

Figure 2 shows the Resource Node installed in the modal test stand at MSFC. This is the launch configuration of Mission STS-88. The structure is held in place by four trunnions (two on each side) and a keel fitting at the bottom. The PMAs attached to the axial ports of the Node are not flight hardware, but are simple mass simulators. The Node was thoroughly instrumented with 1236 accelerometers consisting of 412 triaxial locations as shown in Fig. 3. Three shakers located at the aft end of the payload excited it in each of the $x, y$, and $z$ directions. Note in Fig. 3 that there are several internal instrumented components. The internal elements are 4 forward and 4 aft endcone support structures, 4 alcove and 4 midbay support structures, and one standard Space Station instrumentation rack. Each of the five Shuttle attachment points is also heavily instrumented with triaxial accelerometers.



Fig. 2 - Modal Test Configuration

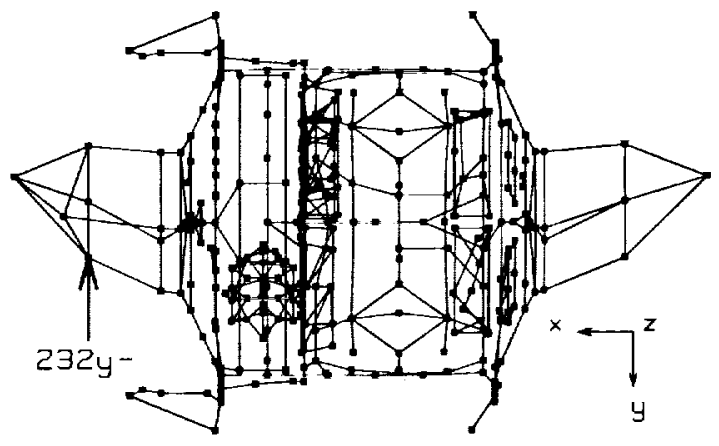

Top View

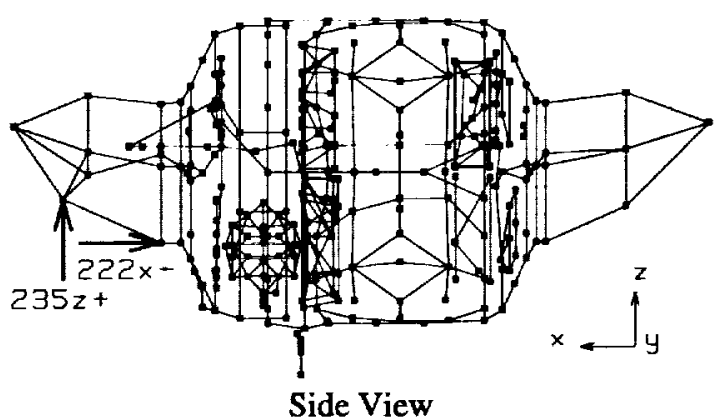

Fig. 3 - Excitation and Response Locations (3 Shakers \& 412 Triaxial Accelerometers)

The structure was excited with uncorrelated, burstrandom excitation by all three shakers simultaneously. A 224-channel data acquisition system measured the accelerometer signals in six sequential data sets. For each data set the shakers ran for approximately $\mathbf{5 5}$ minutes to 
generate frequency response functions with 100 ensemble averages. There is a total of 3708 FRFs ( $3 \times 1236)$, each having 1600 lines of resolution up to $50 \mathrm{~Hz}$.

\section{DATA OVERVIEW}

Figure 4 shows a typical acceleration/force frequency response function. This is the driving-point measurement for the $\mathrm{x}$-direction shaker. Note that the phase angle oscillates entirely between 0 and 180 degrees because the excitation and response degrees-of-freedom coincide. This FRF displays approximately 25 resonances from 8 to $50 \mathrm{~Hz}$. (There are none below $8 \mathrm{~Hz}$.) However, the structure has about 45 modes of vibration in this bandwidth. The other modes are indistinguishable in the plot because either they were not excited by this particular shaker or they are too close in frequency to another mode to be observed.

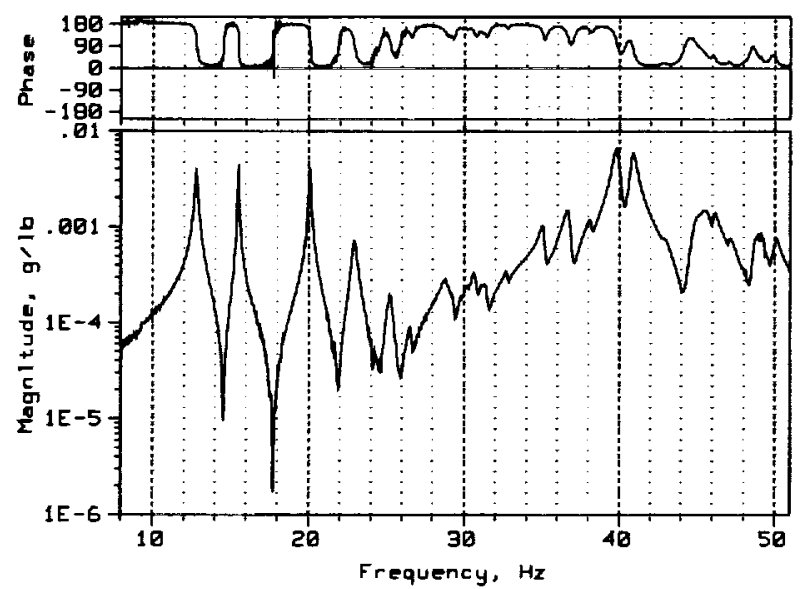

Fig. 4 - Driving-Point Frequency Response (Pt. 222x)
A better way to determine the number of modes in this frequency range is by counting the dips in the multivariate mode indicator function (MMIF) (Ref. 9). Because there were three shakers in the test, there are three indicator functions: a primary, secondary, and tertiary. These functions derive from the complete set of FRFs by solving a third-order eigenvalue problem at each of the 1600 frequency lines. Figure 5 shows the primary and secondary MMIFs. The tertiary function is not plotted because it contains no significant additional information. Due to the relatively low damping of the structure, as well as the high resolution of the measurements, the primary indicator function dips sharply and deeply at each mode. The secondary indicator function dips at frequencies where additional, closely spaced modes occur.

To a significant degree, the MMIF results in Fig. 5 indicate reliably and precisely the natural frequencies of the modes of vibration. However, they provide no corresponding mode shape or damping information. Also, there is a fair amount of uncertainty concerning the number of modes in those frequency intervals with overlapping and/or shallow dips.

\section{ERA MODAL IDENTIFICATION RESULTS}

The Eigensystem Realization Algorithm (ERA) is a multiple-input, multiple-output, time-domain technique that uses all available frequency response functions simultaneously to calculate the natural frequencies, damping factors, and mode shapes of a structure (i.e., its modal parameters) (Refs. 6-8,10). Figure 6 shows the results obtained in this application by analyzing the

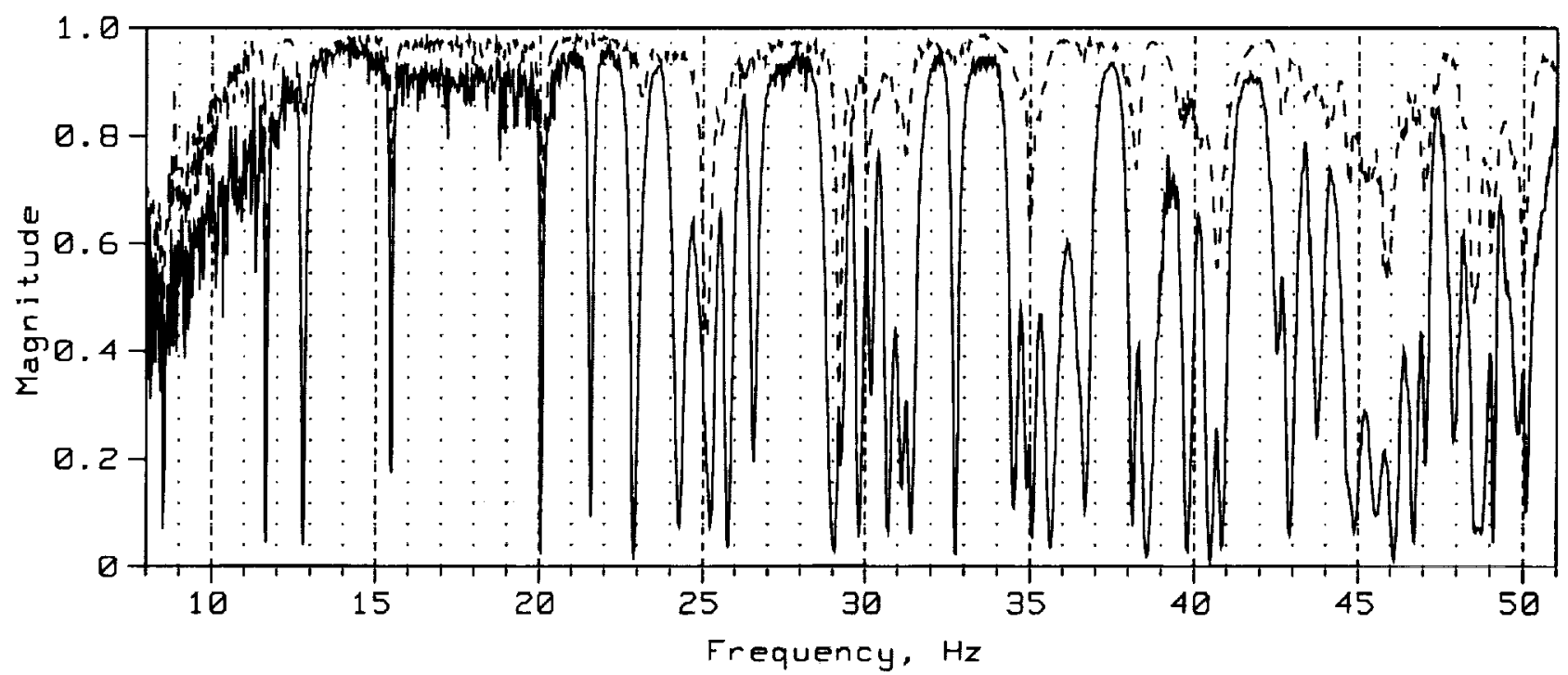

Fig. 5 - Mode Indicator Functions (Solid Line: Primary, Dashed Line: Secondary) 

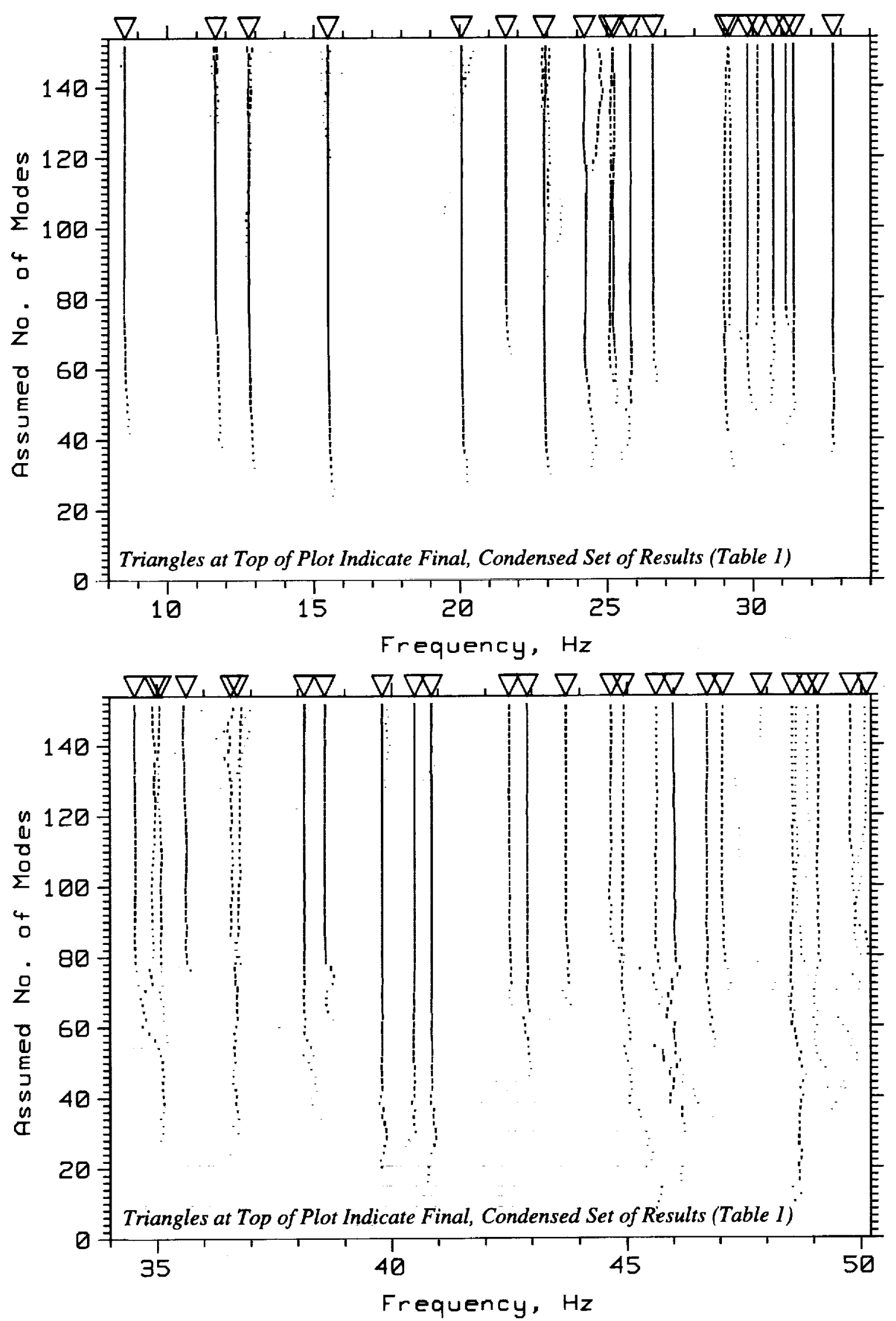

Fig. 6 - ERA-Identified Natural Frequencies vs. Assumed Number of Modes 
entire set of 3708 FRFs simultaneously using a wide range of assumed number of modes from 2 to 150 in steps of 2. Each row of results shows the set of ERA-identified natural frequencies obtained with the specified number of assumed modes. (There are a total of 75 rows.) Each identified mode is represented by a short vertical dash at the associated frequency. The height of the dash is directly proportional to the Consistent-Mode Indicator (CMI), the principal accuracy indicator of ERA (Ref. 10). Modes with CMI values greater than approximately $80 \%$ are identified with high confidence. Modes with values ranging from $80 \%$ to $1 \%$ display moderate to large uncertainty. Fictitious "computational modes" have values of approximately zero. For clarity, the plots exclude all results with CMI values less than $10 \%$.

Note that Fig. 6 is divided into two frequency bands (8-34 $\mathrm{Hz}$ and $34-50 \mathrm{~Hz}$ ). This is done for plotting purposes only. Each of the 75 ERA cases generated the complete set of frequencies shown. The plots begin at $8 \mathrm{~Hz}$ because there are no modes below this frequency. The plots extend to slightly above $50 \mathrm{~Hz}$, the maximum frequency of interest.

A mode with a CMI of $100 \%$ has a vertical dash height in Fig. 6 equal to the distance between minor tic marks on the $y$ axis. Similarly, a mode with a CMI of $50 \%$ has a vertical dash height of one-half the distance between minor tic marks on the $y$ axis. Therefore, those results appearing as solid vertical lines have higher confidence than those appearing as dashed or dotted lines. (Low confidence normally indicates uncertainty in the calculated damping value, mode shape, or frequency, in that order.) Clearly, these ERA results display a wide range of confidence as a function of the assumed number of modes as well as from mode to mode. This is normal for complex experimental data sets due to a variety of "real world" effects including nonlinearity, suboptimal excitation, measurement noise, and closely spaced natural frequencies (particularly if the corresponding mode shapes are similar).

Figure 6 contains a total of 2367 mode estimates. Each mode estimate includes a natural frequency, damping factor, mode shape, and CMI value. Frequency, damping, and CMI are scalar quantities, whereas each mode shape is a 1236-component complex vector. A reliable, automatic procedure has been developed to sift through such large sets of results and extract the best, unique set of modes. This procedure originated as a mode condensation algorithm for autonomous system
Table 1 - ERA Results

\begin{tabular}{|c|c|c|c|c|}
\hline $\begin{array}{c}\text { Mode } \\
\text { No. }\end{array}$ & $\begin{array}{c}\text { Frequency, } \\
\mathrm{Hz}\end{array}$ & $\begin{array}{l}\text { Damping } \\
\text { Factor, \% }\end{array}$ & $\underset{\%}{\mathrm{CMI}}$ & $\underset{\%}{\text { MPC-W, }}$ \\
\hline 1 & 8.562 & 0.358 & 95.5 & 97.3 \\
\hline 2 & 11.651 & 0.342 & 97.2 & 99.2 \\
\hline 3 & 12.776 & 0.600 & 96.3 & 98.6 \\
\hline 4 & 15.481 & 0.191 & 98.7 & 99.5 \\
\hline 5 & 20.059 & 0.259 & 94.9 & 95.8 \\
\hline 6 & 21.583 & 0.348 & 87.9 & 97.4 \\
\hline 7 & 22.888 & 0.594 & 93.8 & 98.3 \\
\hline 8 & 24.245 & 0.941 & 95.4 & 99.0 \\
\hline 9 & 25.093 & 0.622 & 89.2 & 97.6 \\
\hline 10 & 25.221 & 0.763 & 91.5 & 98.7 \\
\hline 11 & 25.781 & 0.686 & 93.5 & 97.2 \\
\hline 12 & 26.565 & 0.579 & 90.7 & 98.9 \\
\hline 13 & 29.045 & 0.857 & 76.7 & 94.7 \\
\hline 14 & 29.182 & 0.574 & 77.7 & 94.0 \\
\hline 15 & 29.810 & 0.500 & 90.7 & 95.0 \\
\hline 16 & 30.159 & 0.519 & 78.9 & 88.1 \\
\hline 17 & 30.699 & 0.543 & 92.5 & 96.2 \\
\hline 18 & 31.131 & 0.500 & 92.4 & 97.7 \\
\hline 19 & 31.404 & 0.532 & 94.8 & 97.2 \\
\hline 20 & 32.732 & 0.313 & 97.6 & 99.7 \\
\hline 21 & 34.524 & 0.509 & 86.7 & 97.6 \\
\hline 22 & 34.970 & 0.291 & 78.0 & 86.2 \\
\hline 23 & 35.074 & 0.428 & 75.1 & 81.8 \\
\hline 24 & 35.621 & 0.515 & 83.9 & 96.4 \\
\hline 25 & 36.573 & 0.727 & 59.5 & 72.6 \\
\hline 26 & 36.708 & 0.348 & 80.0 & 90.8 \\
\hline 27 & 38.132 & 0.419 & 92.1 & 97.7 \\
\hline 28 & 38.570 & 0.390 & 94.9 & 99.9 \\
\hline 29 & 39.796 & 0.503 & 94.0 & 95.6 \\
\hline 30 & 40.495 & 0.607 & 94.7 & 98.3 \\
\hline 31 & 40.859 & 0.488 & 95.9 & $\overline{97.2}$ \\
\hline 32 & 42.512 & 0.509 & 79.3 & 98.8 \\
\hline 33 & 42.904 & 0.521 & 88.8 & 98.5 \\
\hline 34 & 43.716 & 0.692 & 68.9 & 95.7 \\
\hline 35 & 44.657 & 0.349 & 73.4 & 95.0 \\
\hline 36 & 44.928 & 0.747 & 58.5 & 68.5 \\
\hline 37 & 45.622 & 1.015 & 58.0 & 77.5 \\
\hline 38 & 45.983 & 0.401 & 90.8 & 97.6 \\
\hline 39 & 46.710 & 0.426 & 76.4 & 86.4 \\
\hline 40 & 47.046 & 0.366 & 61.6 & 79.0 \\
\hline  & 47.870 & 0.923 & 10.9 & 58.3 \\
\hline 42 & 48.540 & 0.482 & 25.7 & 32.2 \\
\hline 43 & 48.852 & 1.110 & 12.7 & 23.7 \\
\hline 44 & 49.077 & 0.297 & 56.3 & 71.7 \\
\hline 45 & 49.762 & 0.564 & 62.5 & 84.4 \\
\hline 46 & 50.109 & 0.462 & 22.0 & 60.9 \\
\hline
\end{tabular}

identification (Ref. 8). Application of this condensation algorithm to the data in Fig. 6 resulted in the 46 natural frequencies marked by triangles at the top of the plots. The results are also listed in Table 1, including the corresponding damping factors, CMI values, and 
Weighted Modal Phase Collinearity (MPC-W). As mentioned previously, CMI is the principal ERA accuracy indicator. It normally provides a reliable, single measure of accuracy for each mode. MPC-W supplements CMI and indicates the nearness of the mode shape to a monophase vector (i.e., to a classical normal mode) (Ref. 10). Values greater than $95 \%$ are extremely high. High MPC-W values are particularly meaningful, and harder to achieve, when there are a large number of measurements. In this application, 29 of 46 modes (63 percent) have values of $95 \%$ or greater.

The ERA analysis shown in Fig. 6 required a few hours of CPU time on a UNIX workstation using a FORTRAN implementation. The mode condensation procedure that extracted the 46 best, unique modes from the total set of 2367 mode estimates required several additional minutes of computer time. These two steps ran sequentially with only a slight amount of user interaction necessary (i.e., almost autonomously).

\section{COMPARISON OF RESULTS}

This final section of the paper compares the ERA results in Table 1 with the MSFC results given in Ref. 5. First, the mode shapes are compared using the Modal Assurance Criterion (MAC) (Ref. 11). MAC is the square of the inner product of normalized (unit length) modeshape vectors. This is the same parameter referred to in statistics as the square of the correlation coefficient. Values greater than approximately $80 \%$ indicate a high degree of similarity. Secondly, the natural frequencies and damping factors of the correlated pairs of ERA and MSFC modes are compared, and the differences are plotted versus Mode Number.

Figure 7 shows the correlation of all ERA-identified modes with all MSFC-identified modes using MAC. The plot has a simple graphical format as follows. Each row and column represents one mode. The MAC value for each pair of modes is proportional to the size of the rectangle drawn at the intersection of the corresponding row and column. For example, ERA Mode 22 and MSFC Mode 22 have a MAC value of $55 \%$, and the corresponding intersection contains a rectangle whose width and height are $55 \%$ of the $x$ and $y$ dimensions of the intersection, respectively. Values of $80 \%$ or greater are darkened for emphasis.

Figure 7 indicates a very good, one-to-one correspondence of the majority of ERA and MSFC mode shapes. In particular, the first 21 pairs of modes from the two independent data analyses are essentially identical. All of these MAC values are extremely high-above

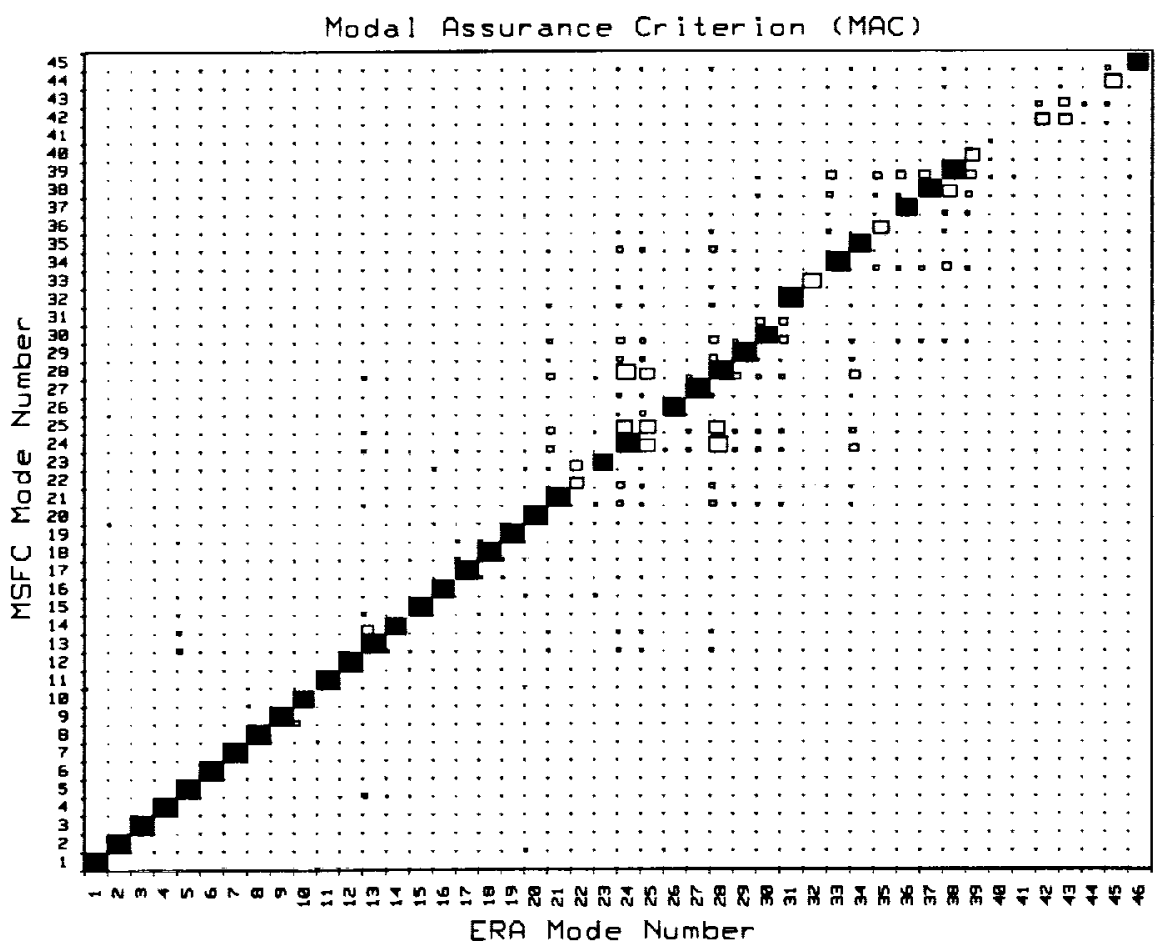

Fig. 7 - Correlation of ERA and MSFC Mode Shapes Using the Modal Assurance Criterion (MAC). MAC Values of $80 \%$ or Greater Are Darkened. 
95\%-except Modes 10 (87\%), 14 (85\%), and $16(92 \%)$. Modes 22 and higher show greater deviation from unique, one-to-one correlation. However, the overall similarity of the two sets of results is still very good all the way up to ERA Mode 39 at $46.7 \mathrm{~Hz}$. Fourteen of $25 \mathrm{high}$-frequency modes (56 percent) starting at Mode 22 have excellent MAC values of $80 \%$ or greater.

The 21 low-frequency modes with high MAC values (up to $34.5 \mathrm{~Hz}$ ) are the most significant from a loads and deformation standpoint. The analytical transient analysis for structural verification of Shuttle payloads uses all modes of the combined Shuttle/payload model up to 35 $\mathrm{Hz}$ (Ref. 2). Of course, since some modes of the payload above $35 \mathrm{~Hz}$ may drop below this frequency when it is combined with the Orbiter, the recommended goal is to obtain test-verified payload models up to $50 \mathrm{~Hz}$.
Figure 8 shows the MAC, frequency difference, and damping difference of each pair of correlated modes. The 35 pairs of modes with MAC values of at least $80 \%$ are darkened in all three plots. This was done to investigate if low MAC values correlate with large frequency and/or damping differences. Surprisingly, there is not a significant trend of this type. For example, although the three largest frequency differences in Fig. 8(b) occur for modes with MAC values below $80 \%$, three other modes with values below $80 \%$ have frequency differences less than $0.025 \mathrm{~Hz}$. Similarly, Fig. 8(c) shows no consistent trend of low MAC values with large damping differences. Overall, there is excellent agreement of the ERA and MSFC natural frequencies and damping factors, with 40 pairs of modes having a frequency difference of less than $0.1 \mathrm{~Hz}$ and 39 pairs of modes having a damping difference of less than 0.2 percent.

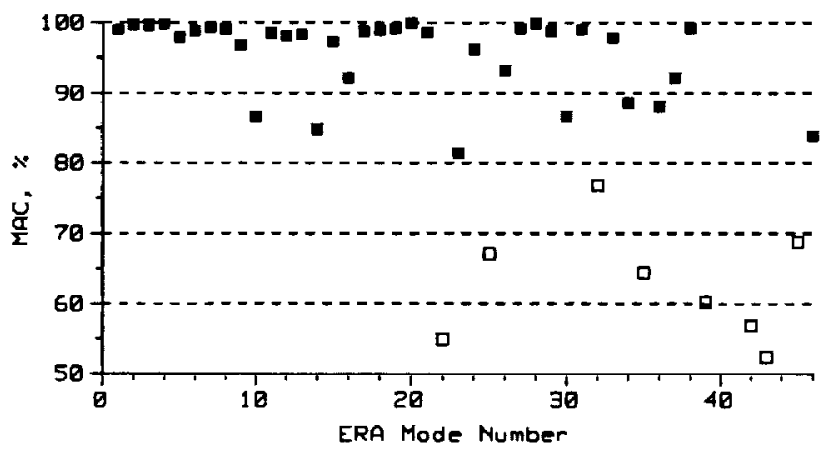

(a) Modal Assurance Criteria (Similarity of Mode Shapes)

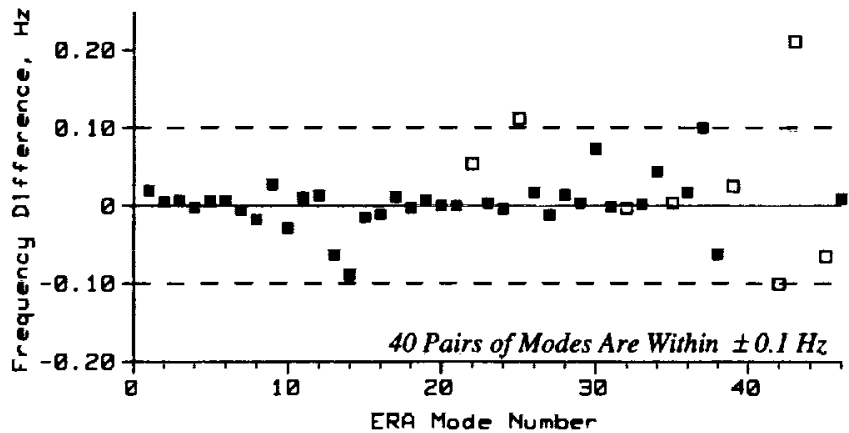

(b) ERA Frequencies Minus MSFC Frequencies



(c) ERA Damping Factors Minus MSFC Damping Factors

Fig. 8 - Comparison of ERA and MSFC Mode Shapes, Frequencies, and Damping. Mode Pairs With MAC of $80 \%$ or Greater are Darkened. 


\section{CONCLUSIONS}

This paper compared independent modal identification results for the Space Station Resource Node obtained at NASA Langley Research Center using ERA and at NASA Marshall Space Flight Center using commercial software. The Resource Node is the first U.S.-built structure for the International Space Station. Each organization analyzed a large set of 3708 frequency response functions ( 3 shakers and 1236 accelerometers), with approximately 45 modes of vibration in the test bandwidth of 0 to $50 \mathrm{~Hz}$. The ERA analysis and mode condensation procedure required a few hours of CPU time on a UNIX workstation, and they ran sequentially with only a slight amount of user interaction necessary (i.e., almost autonomously). Overall, there was excellent similarity of mode shapes, natural frequencies, and damping factors for the majority of ERA- and MSFCcalculated modes. This correlation of independent results allows the analytical model validation effort for the Space Station Resource Node to proceed with increased confidence in the accuracy and completeness of the experimental modal parameters.

\section{ACKNOWLEDGMENTS}

The author thanks Danny Coleman, Blaine Anderson, Kathy Chandler, and Tim Driskill of MSFC and Byron Calvert, Ed Phillips, Steve Woletz, Conrad Ball, and Steve Radke of Boeing for their assistance and support in this cooperative effort.

\section{REFERENCES}

1. Ronalds, H., "International Space Station," Website: http://station.nasa.gov, September 1997.

2. Lambert, C. H., Jr., "Payload Verification Requirements," Space Shuttle Program, NASA Johnson Space Center Report NSTS 14046, Revision C, April 1994.

3. Foster, R. M., "Structural Design and Verification Requirements," International Space Station Program, NASA Johnson Space Center Report SSP 30559, Revision B, June 1994.
4. Chandler, K. O., Anderson, J. B., Coleman, A. D, and Driskill, T. C., "Modal Testing of the International Space Station Resource Node," Proceedings of the 16th International Modal Analysis Conference, Santa Barbara, CA, February 1998.

5. Anderson, J. B., Chandler, K. O., Driskill, T. C., and Coleman, A. D., "ISS Resource Node Fixed Base Modal Survey Test Report," NASA Marshall Space Flight Center Report SS-DEV-ED96-112, February 1997.

6. Juang, J.-N. and Pappa, R. S., "An Eigensystem Realization Algorithm for Modal Parameter Identification and Model Reduction," Journal of Guidance, Control, and Dynamics, Vol. 8, No. 5, September-October 1985, pp. 620-627.

7. Pappa, R. S., "ERA Bibliography," Website: http://sdbwww.larc.nasa.gov/SDB/Research/data/ERA_biblio.html, September 1997.

8. Pappa, R. S., Woodard, S. E., and Juang, J.-N., "The Development of Autonomous Structural Modal Identification," Sound and Vibration, August 1997, pp. 18-23.

9. Williams, R., Crowley, J., and Vold, H., "The Multivariate Mode Indicator Function in Modal Analysis," Proceedings of the 3rd International Modal Analysis Conference, Orlando, FL, January 1985, pp. 6670.

10. Pappa, R. S., Elliott, K. B., and Schenk, A., "Consistent-Mode Indicator for the Eigensystem Realization Algorithm," Journal of Guidance, Control, and Dynamics, Vol. 16, No. 5, September-October 1993, pp. 852-858.

11. Allemang, R. J. and Brown, D. L., "A Correlation Coefficient for Modal Vector Analysis," Proceedings of the Ist International Modal Analysis Conference, Orlando, FL, November 1982, pp. 110-116. 
Public reporting burden for this collection of information is estimated to average 1 hour per reponse, inclucing the time for revlewhy instructions, searching existing deti sourcec. pethering and maintaining the data nesded, and completing and reviewing the collection of intormation. Send comments regerding this burden estimate or any other alpect of this

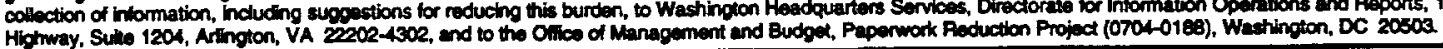

\begin{tabular}{|l|l|l}
\hline 1. AGENCY USE ONLY (Leave blenk) & $\begin{array}{l}\text { 2. REPOFT DATE } \\
\text { December 1997 }\end{array}$ & $\begin{array}{l}\text { 3. REPOFT TVPE AND DATES COVERED } \\
\text { Technical Memorandum }\end{array}$
\end{tabular}

4. TIILE AND SUBTITE

Independent Analysis of the Space Station Node Modal Test Data 5. FUNDWG NUMBERS

WU 522-32-41-02

6. AUTHOR(S)

Richard S. Pappa

7. PERFORMING ORGANIZATION MAME(S) AND ADORESS(ES)

NASA Langley Research Center

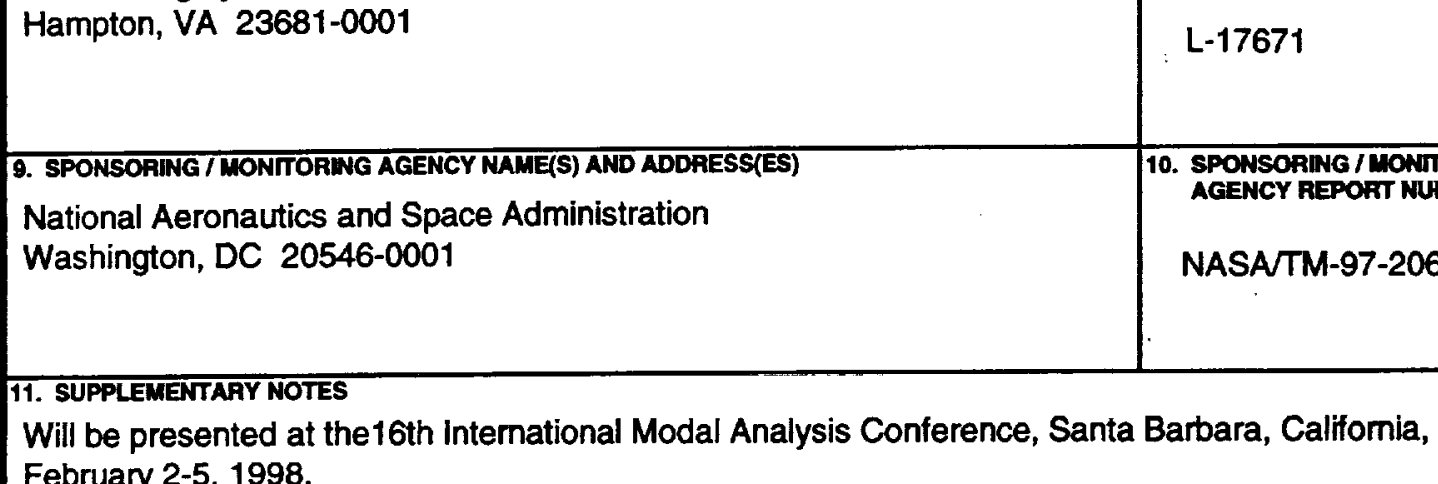

8. PERFOFIMG OAGANEATION

REPOHT NUMBER

February 2-5, 1998.

12a. DISTRIBUTON/AVAILABILTY STATEMENT

12b. DESTRIBUTION COOE

Unclassified - Unlimited

Subject Category 39

Distribution: Nonstandard

\section{ABSTRACT (Mindmum 200 words)}

With complex structures, comparison of independently derived sets of experimental modal parameters is an excellent way to increase confidence in the results. This paper presents modal identification results using the Eigensystem Realization Algorithm (ERA) on frequency response functions from the modal test of the Space Station Resource Node. The Resource Node is the first U.S.-built structure for the International Space Station. The modal test was conducted by the NASA Marshall Space Flight Center (MSFC) in January 1997 for the Boeing Company, who designed and buitt the Node. The ERA-calculated parameters are compared with independent results obtained by the MSFC test team using commercial software. There was excellent correlation of mode shapes between the two sets of results for the first 21 vibration modes of the structure up to $35 \mathrm{~Hz}$. From 35 to $50 \mathrm{~Hz}$, about 60 percent of 25 additional modes had excellent correlation. Natural frequencies and damping factors of most modes agreed within $0.1 \mathrm{~Hz}$ and 0.2 percent, respectively.

\section{SUBJECT TERISS}

International Space Station, Space Station Resource Node, modal testing, vibration testing, spacecraft structural verification, experimental modal parameters, Eigensystem Realization Algorithm.

\begin{tabular}{l|l|l}
\hline $\begin{array}{l}\text { 17. SECUATY CLASSIFICATION } \\
\text { OF REPORT } \\
\text { Unclassified }\end{array}$ & $\begin{array}{l}\text { 18. SECUFTY CLASSIFICATION } \\
\text { Of This PAGE } \\
\text { Unclassified }\end{array}$ & $\begin{array}{l}\text { 19. SECUATY CLASSIFICATION } \\
\text { Of ABSTRACT }\end{array}$
\end{tabular}

NSN 7540-01-280-5500
15. ML TREA OF PACES

13

16. PAICE CODE

A03

20. UWTATON OF ABSTRACT

Standerd Form 200 (Rer 200)

Presctibed by ANSI Sid. Z60-18 202100 
